\title{
Effective Regulation and Level of Awareness: An Exposé of the Nigeria's Construction Industry
}

\author{
Ikechukwu A. Diugwu, Dorothy L. Baba, Ashem E. Egila \\ Department of Project Management Technology, Federal University of Technology, Minna, Nigeria \\ Email: i.diugwu@aim.com, i.diugwu@futminna.edu.ng
}

Received August 28, 2012; revised October 3, 2012; accepted October 18, 2012

\begin{abstract}
The preparedness of any organization to minimize the frequency and severity of work related accidents, ill-health, and damage to property is demonstrated by the adoption of a health and safety management system. By its nature, a health and safety management system through its provisions and demands, not only highlights the impact of poor health and safety standards on organizational performance but also encourages greater awareness of health and safety issues and responsibilities. Quite unfortunately, in Nigeria (as in many developing economies) statutory regulation, capable of ensuring the adoption and implementation of health and safety management systems by organizations, seems inadequate or ineffective. The impact of this, as demonstrated by the outcome of survey and literature review, is a general lack of awareness on important health and safety issues among Nigerian construction workers. Equally, there is an inability and or unwillingness by organizations to pay adequate attention to health and safety management. Consequently, the overall health and safety standard, operational capability and corporate image of Nigeria's construction industry have been affected.
\end{abstract}

Keywords: Health and Safety Management; Construction; Health and Safety Management System; Safety Regulation

\section{Introduction}

The failure by employers to provide safe and conducive work environment, or the inability to use these facilities appropriately by employees, has cost implications on individuals, organizations, and the society [1-4]. The adoption of a health and safety management system (HSMS) demonstrates in practical terms, the readiness of an organization to minimize the frequency and severity of work related accidents, ill health, and damage to property. This is because the provisions and requirements of HSMS encourage greater awareness of responsibilities and aspects of health and safety, highlighting the impact of poor health and safety standards on the performance of organizations [5]. However, the potency of HSMS in minimizing the frequency and severity of work related accidents, injuries, ill-health, loss and damage to property is rooted in the existence of functional health and safety laws. Health and safety laws ensure that organizations safeguard the health, safety and welfare of workers and visitors by protecting them from risks emanating from their work activities, and that employees use facilities and resources provided by their employers in a manner that will neither lead to property damage nor put them or others at risk [6]. Typical examples of health and safety Acts and regulations include The Factory Act of 1990 (Nigeria—an adaptation of UK Factory Act of 1961), the Occupation Safety and Health Act of 1970 (USA), the Control of Substance Hazardous to Health Regulations of 1988 (UK), the Personal Protective Equipment at Work Regulations of 1992 (UK), the Management of Health and Safety at Work Regulations of 1999 (UK), The Manual Handling Operations Regulations of 1992 (UK), the Construction Design and Management Regulations of 2007 (UK).

In spite of these statutory provisions and expectations, there is still a gap in health and safety management in Nigeria. This gap is largely due to a dysfunctional health and safety law, causing an apparent lack of regulation of health and safety in almost every sector of the economy. For instance, [7] observes that Nigeria lacks requisite statutory regulations on health and safety. The promulgated ones, notably the Factory Act, are skeletal in nature and non-functional, and may not have been adapted to the Nigerian society as they originated from foreign countries such as UK and US; actually, it is only the Factory Act that has a Nigerian version [8]. The Factory Act of 1990 establishes both the statutory basis for inspection and enforcement of health and safety conditions in factories and ensures that systems and structures for reporting accidents and injuries (where necessary) are put in place. It also stipulates the nature of punishments for non-com- 
pliance. These provisions notwithstanding, contractors in Nigeria's construction industry are left to use their discretion in managing health and safety issues. Consequently, contractors allocate little resources to health and safety management, rarely keep, report, or release accurate records of accidents and injuries occurring at their work sites [8].

With specific reference to the construction industry, there are inherent limitations of the Factory Act (1990) which affect its effective application. The provisions of the Factory Act of 1990 (by omission or commission) exclude some industry sectors from abiding by its requirements and provisions. For instance, it does not provide for the mandatory use of personal protective equipment within the construction industry as provided for in the Personal Protective Equipment (PPE) Regulations of 2002 of UK. Specifically, although Articles 47 and 48 of the Factory Act (1990) stipulate the provision of PPE for workers [8], citing [9], notes that the definition of a factory as given in Article 87 of the same Act technically excludes construction sites and associated activities from the coverage of the Act.

In view of the above, [8] notes that the inadequate regulation of health and safety in the industry as a result of the forgoing limitations in the provisions of the law, leads to a dearth of accurate records on health and safety performance, thus making it almost impossible to have any meaningful improvement in health and safety standards of construction firms in Nigeria. Quite naturally, the absence of functional and stringent health and safety regulations could impact negatively on health and safety performance as organizations are seemingly not dutybound to establish management systems that could improve safety awareness and standards. The research reported here seeks to fill this gap by establishing the level of awareness of health and safety issues by construction workers in Nigeria, and how health and safety regulation has contributed to this.

\section{Overview of the Construction Industry}

\subsection{Economic Contribution}

The construction industry is regarded as the pillar of the domestic economy in many countries. For instance, the Office for National Statistics [10] notes that at the end of the third quarter of 2011, there were over 2 million people employed in multiple roles in over 250,000 construction firms in UK; with about $£ 75$ billion contribution to the UK economy in 2008 [11]. A similar impact is noticeable in Nigeria, where [12] note that the industry has contributed substantially to economic growth $(5 \%-7 \%$ improvement in the GDP growth, and over $42 \%$ of the fixed capital growth) over the last four decades.

\subsection{Health and Safety Outlook}

The immense contributions of the construction industry to economic growth notwithstanding, the frequency and severity of accidents and ill health in the sector pose great concern to stakeholders. As an example, the UK construction industry accounted for about $40.7 \%$ of deferred prohibitions, $59.6 \%$ of immediate prohibitions, and $30.8 \%$ of total notices issued by Health and Safety Executive (HSE) for the period 2003/2004 [13]. This, according to [14], shows a prevalently higher level of recorded fatal injuries and major accidents in the construction industry than in most other sectors of the economy. A similar view to that expressed by [14] could be held about the about Spanish construction industry which has its fatality figure fluctuating between 250 and 300 every year [15]. These accidents, ill health and damages to property also have a direct impact on the livelihood of citizens, as statistics show that there are about 6300 fatalities per day in the construction industry [16]. The provisional 2010/2011 statistics released by [17] shows that the UK construction industry has the greatest number of fatal injuries, having accounted for about $29 \%$ of all fatal injuries to workers in 2010/2011.

Although the sources of these accidents and ill health vary, majority of the fatalities in the UK construction industry result from falls from roofs, scaffolds and ladders, falling objects and materials, transportation equipment, (e.g. excavators and dumpers), excavation work, etc. $[18,19]$. The $2010 / 2011$ provisional statistics by the [17] shows that the construction sector accounted for $28 \%$ of all reported injuries to employees resulting from handling, 23\% from slips and trips, 26\% (247 cases) from high falls, 29\% (32 cases from collapses, 25\% (3 cases) of drowning/asphyxiation, $16 \%$ (70 cases) involving electricity and $16 \%$ (10 cases) from explosions.

An interesting observation is that most of the reported fatalities, injuries, ill health and damage to property statistics are from developed economies. This may give an impression that there are prevalently more accidents in developed countries such as UK and USA than in developing and third world countries (such as Nigeria). This may well be a misconception! The volume of statistics from the developed countries is caused less by poor health and safety standards but more by the existence of functional health and safety laws and regulations with stringent enforcement and requirement for the establishment of management systems which ensure that accurate records of incidents and accidents at work are kept and reported to appropriate authorities. However, this is not the case in some other countries with dysfunctional health and safety laws and regulations. Nigeria falls within this category of countries, where organizations allocate little resources to health and safety management, 
rarely keep, report, or release accurate records of accidents and injuries on site, leading to poor health and safety performance [8].

Effective management of health and safety is motivated by various factors. This could be predicated on the need to abide by extant rules and regulations (the legal point of view), a consideration of human lives that are involved (socio-humanitarian perspective), or on the direct and indirect cost involved (financial-economic perspective) [20]. These views apply to different countries in different ways. In Nigeria, for instance, where there is inadequate regulation of health and safety, this could be influenced more by the socio-humanitarian and financial-economic consequences of accidents and injuries at work than by the legal implication (or the need to abide by statutory requirements).

\section{Materials and Methods}

\subsection{Study Area}

A geographical location for data collection was identified in line with guidelines [21]. Subsequently, the survey samples were geographically restricted and collection of data used in this study was restricted to Minna, Nigeria. In order to aid clarity of presentation, percentages would be presented in rounded figures (where necessary) in line with the suggestion by [22].

Although sampling was restricted to a given geographic area, in line with [23], questionnaires were randomly distributed to ensure that sampling was not restricted to an enterprise size band. This was with a view to avoiding a skewed analysis by obtaining a representative view on the questions asked, thus avoiding a skewed analysis. This method is an economical way to sample without losing the characteristics of the probability sample [23, 24]. These notwithstanding, there is a likelihood of bias and sampling error in the choice of respondents [23], as well as the extent of homogeneity or representativeness of respondents. Nonetheless, the authors are confident that this technique would not skew the results [23].

\subsection{Sample Size Determination}

In an exercise of this nature, it is not feasible to poll every stakeholder in the construction industry; a representative population is surveyed. An appropriate sample size that would not skew the outcome of the survey could be determined using the formula proposed by [25,26]. In this work, it is assumed that construction workers are normally distributed in their interpretation of health and safety requirements. In view of the fact that this assumption is similar to that underlying the Yamane's formula, the original equation from which the Yamane formula was derived from was chosen in preference to the Coch- ran formula:

$$
n=\frac{z^{2} P(1-P) N}{z^{2} P(1-P)+N(\mathrm{e})^{2}}
$$

where:

$$
\begin{aligned}
& n=\text { sample size } \\
& N=\text { population size }(40,000) \\
& Z=\text { standard normal variable }(z=1.96 \text { at } 95 \% \text { confi- } \\
& \text { dence level }) \\
& P=\text { proportion or degree of variability }=50 \% \\
& e=\text { the level of precision }=5 \% \text {. } \\
& \text { The above formula yields a sample size }(n)=381 \text {. A }
\end{aligned}
$$
further $30 \%$ (114) of this figure was built in to compensate for non-responses in line with the suggestion by [27]. Thus, a total a 495 questionnaires were distributed randomly to construction workers in Minna.

\subsection{Data Assembly and Management}

The questionnaire elicited views on varying aspects of health and safety such as awareness of health and safety management, existence of health and safety policy, motivations for health and safety management, constraints to health and safety management, among others. The questions were informed by earlier works in health and safety management [5,28-30]. The questionnaire was piloted to ascertain clarity and relevance of questions asked before they were finally distributed to respondents.

As an exploratory research, analyses carried out are mostly frequency analysis of relevant variables, as the primary concern is to ascertain level of awareness and not to make any inferential deductions.

\section{Results and Discussion}

\subsection{Distribution of Respondents}

From a total of 495 questionnaires distributed, 312 were returned consisting of 271 valid and 41 invalid questionnaires. This represents a $69 \%$ response rate. This response rate is in line with the response rates from other surveys on health and safety management in Nigeria [8,31]. The responses to different questions may not total up to 271 because of missing cases (unclear or non-responses).

The analysis of responses to this question revealed that there were about 237 (87.5\%) valid cases and about 34 (12.5\%) classified as missing (unclear or no response). The distribution of the valid responses to this question according to enterprise size and nature of business is shown in Table 1.

\subsection{Implication of Health and Safety Standards}

An analysis of the valid responses shows that 233 (91\%) respondents felt that poor health and safety has an impact 
Table 1. Distribution of respondents.

\begin{tabular}{cccc}
\hline \multirow{2}{*}{ Nature of business } & \multicolumn{3}{c}{ Enterprise size } \\
\cline { 2 - 4 } & $1-9$ & $10-49$ & Total \\
\hline Transportation & 18 & 4 & 22 \\
Masonry & 54 & 20 & 74 \\
Metal works & 29 & 9 & 38 \\
Quarrying & 13 & 5 & 18 \\
Carpentry & 20 & 3 & 23 \\
Plumbing & 17 & 4 & 21 \\
Electrical works & 9 & 7 & 16 \\
Others & 22 & 3 & 25 \\
Total & 182 & 55 & 237 \\
\hline
\end{tabular}

on their business operations, while 22 (9\%) felt it has no impact. With regards to business image, 187 (74\%) respondents felt that poor health and safety standard affects their business image, while 65 (26\%) respondents do not think that their image is affected by safety standard. The above result is in line with conclusions drawn from earlier studies [5], which established that poor health and safety standards affect the operations and image of an organization.

The substantial number of respondents who felt that their business image or operations could be impacted upon by the standard of health and safety shows that with proper motivation and guidance, organizations may be receptive to initiatives that could shield them from the negative impact of workplace accidents and ill health. This is perhaps because an incident or accident causes delay in operations and cost arising from treatment or replacement of damaged items or personnel that are no longer fit. Inferring from above, a safe and healthy workplace, by minimizing the frequency and occurrence of accidents and ill health to workers, leads to improved productivity.

Some interviewees observed that the financial cost of accidents comes from compensations, medical bills, litigation, insurance, repair and replacement costs, as well as from fatalities and injuries. The effect of this on the performance of an organization could come in various ways. For instance, a disruption in the operations of a business associate could have a ripple effect along the supply chain [32]. This is perhaps the reason why safety conscious organizations take proactive steps to ensure that potential problems from their outsourced activities do not affect them [33]. Continuing, [33] notes that this could also limit the human resources at the disposal of an organization as poor safety standard leads to loss of manpower while good health and safety standard leads to low staff turn-over.

\subsection{Awareness of Health and Safety Regulations}

Figure 1 shows the perceived level of awareness of some health and safety regulations by construction workers in Minna, Nigeria.

While the above result seems encouraging, personal observations from various construction sites reveal that although respondents are aware of some regulations, there are little or no tangible evidence to substantiate this.

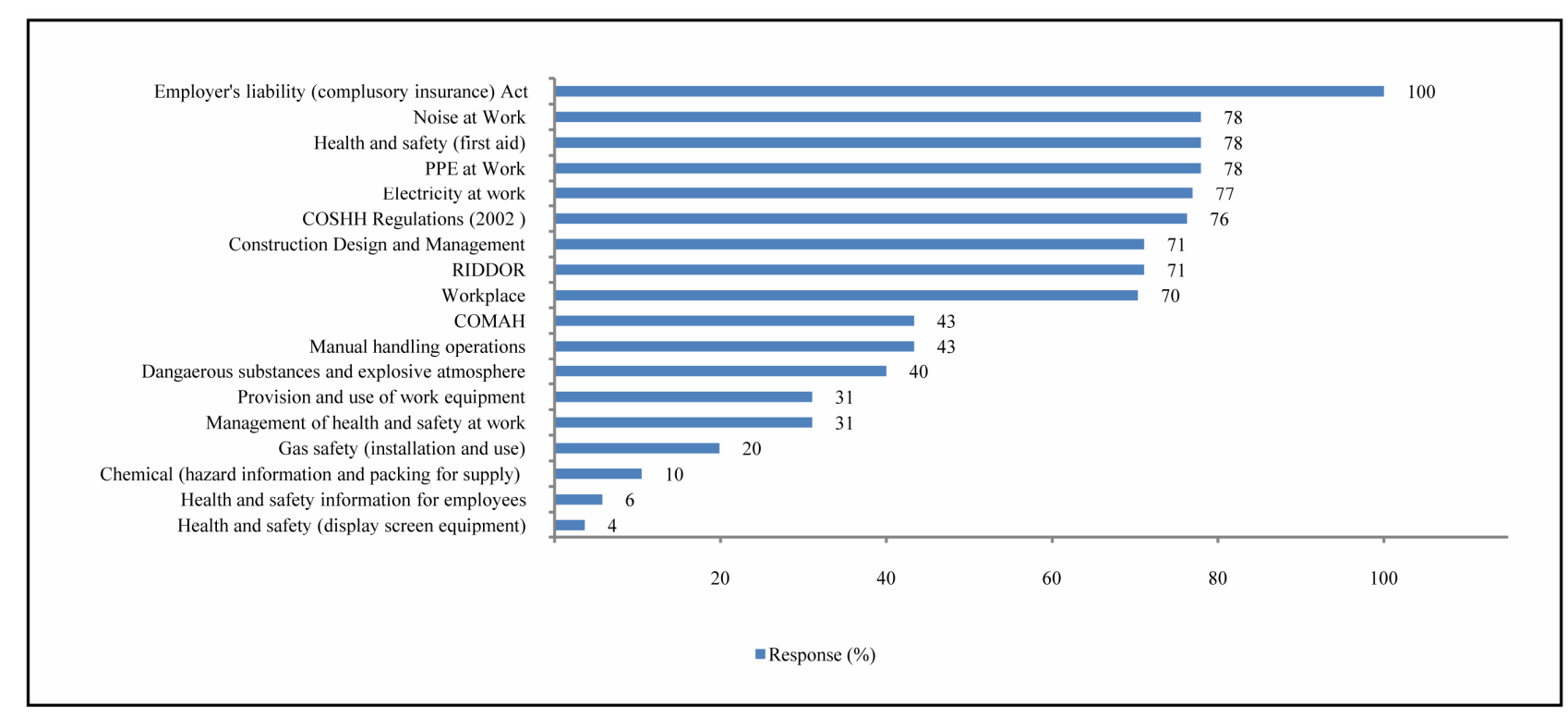

Figure 1. Awareness of health and safety regulations. 
For instance, although many claim to be aware of the noise at work and the personal protective equipment requirements, workers on site were not using high visibility clothing, earmuffs, nose mask, gloves among others. It is either that workers have not been provided with these, or that they have refused to use them. Either or both of the two scenarios point to a weak workplace health and safety management. This observation is strengthened by the small percentage (31\%) of respondents who are aware of the management of health and safety at work and the provision and use of work equipment regulations respectively. Site observations further revealed that workers do not have adequate information about the chemical composition of some of the materials that they work with and how they can be affected by these. This is, again, corroborated by the $6 \%$ that are aware of health and safety information for employees, the chemical hazard information for packing supply (10\%), as well as the dangerous substances and explosive atmosphere regulation (40\%). This is however, at variance with the $76 \%$ that claim to know about the control of substances hazardous to health (COSHH regulations). This suggests that safety of workers is not a priority to those who manage construction companies in Nigeria.

\subsection{Health and Safety Management Policies}

Table 2 shows a breakdown of views on the existence of health and safety management policies in organizations. It suggests that about 104 (44.1\%) of respondents' organizations have some form of health and safety policy distributed s follows: formal health and safety policy (7), policy that requires written/incident reports (9), policy that requires accident/incident investigation to be conducted (37), and a policy that requires the documentation, investigation and discussion of near misses (51). About 132 respondents (55.9\%) expressed a contrary view that they do not have health and safety policies in place.

This indicates that although many construction companies may be aware of the impact of poor health and safety on their activities, they, however, do not have any policy in

Table 2. Evidence of health and safety policies.

\begin{tabular}{ccc}
\hline \multirow{2}{*}{ Policy } & \multicolumn{2}{c}{ Valid responses } \\
\cline { 2 - 3 } & Frequency & $\%$ \\
\hline Formal health and safety policy & 7 & 3.0 \\
Policy that requires written/incident reports & 9 & 3.8 \\
Conduct accident/incident investigation & 37 & 15.7 \\
Document, investigate and discuss near misses & 51 & 21.6 \\
None & 132 & 55.9 \\
Total & 236 & 100 \\
\hline
\end{tabular}

place to ensure safety of their workers. This reinforces the picture painted of Nigeria's construction industry as one with poor health and safety management culture (see Figure 1).

\subsection{Appointment of Health and Safety Representatives}

Out of the 215 valid responses to this question, only 44 (20.5\%) respondents indicated that they have health and safety representative(s), while 171 (79.5\%) said that they do not have any (Figure 2).

This outcome is not surprising as there are no regulations that stipulate or enforce the appointment safety representatives. This could be contrasted with the situation in UK where the Safety Representatives and Safety Committees Regulations 1977 (SRSC Regulations 1977) of the Health and Safety at Work Act 1974, allowed only organizations with organized trade unions to appoint health and safety representatives. This implies that in situations where the management of an organization is not pro-employee safety conscious, there may not be any legally recognized voice to speak on their behalf. This is also in alignment with the outcome of Section 4.3 which suggests a low level awareness and or implementation of certain health and safety regulations.

\subsection{Regulation and Enforcement of Health and Safety}

Figure 3 shows the respondents' views on the body that regulate or enforce health and safety management in Nigeria's construction industry. About 112 (55.2\%) respondents do not know who regulates or enforces compliance with health and safety management in Nigeria, 45 (22.1\%) think it is the local authority's environmental health department, 26 (12.8\%) feel it is the Nigerian Institute of Builders (NIOB), while 20 (9.9\%) feel that this responsibility resides with a Federal Ministry/Agency.

This simply implies that construction workers (and this may be representative of the entire society) do not know whose responsibility it is to regulate health and safety, or enforce compliance.

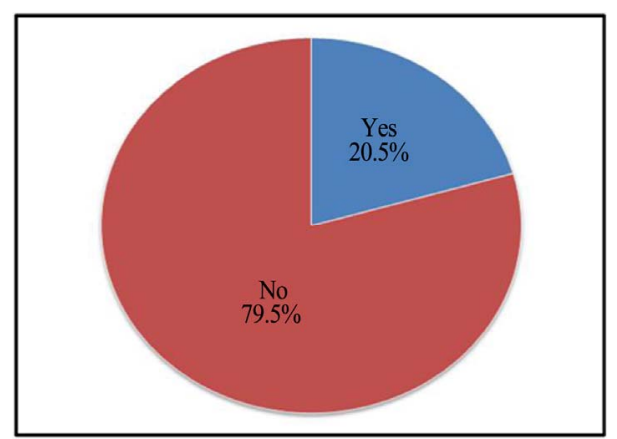

Figure 2. Appointed health and safety representatives. 


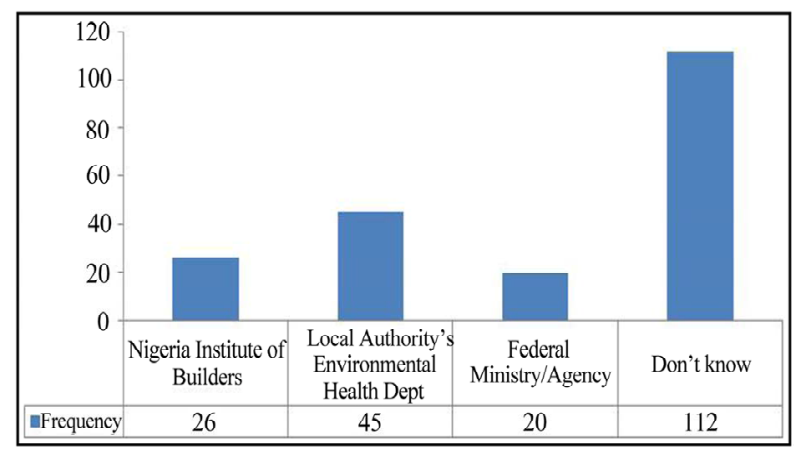

Figure 3. Responsibility for regulation and enforcement.

\subsection{Information on Health and Safety}

There were 242 valid responses to the question on available sources of health and safety information (Table 3).

The result shows that over $62 \%$ of the respondents claim to get their information from health and safety journals, with about $24 \%$ getting these information from regulators and their websites. The result clearly shows the minimal impact of the government (at all tiers) and its agencies in the regulation and management of health and safety in the construction industry. The implication of this is that because not all respondents have access to the internet, information dissemination through this medium becomes less effective.

It could be argued that those respondents who use regulators and their websites may have been accessing websites of regulators in other countries such as the Health and Safety Executive, UK (HSE, UK). If this were to be the case, then the small number of respondents that used this medium could be explained by the low internet penetration and accessibility in Nigeria [34] among other factors.

\subsection{Constraints to Health and Safety Management}

Table 4 shows the responses on factors that affect a company's ability to effectively manage health and safety.

It could be seen that lack of adequate regulation and support are major constraints to an effective health and safety management in Nigeria's construction industry. These factors could have cascaded effects on resources, enlightenment and commitment, which were also identified as constraining factors by respondents.

\section{Conclusions}

This paper has highlighted that lack of effective regulation has impacted on health and safety management in Nigeria's construction industry. This trend if allowed to continue may impact on the contribution of the sector to national economic development. This situation not withstanding, it was established that construction workers,
Table 3. Source of health and safety information.

\begin{tabular}{ccc}
\hline \multirow{2}{*}{ Source } & \multicolumn{2}{c}{ Responses } \\
\cline { 2 - 3 } Trade Union & Frequency & $\%$ \\
Local Authority & 6 & 3 \\
Regulators and their websites & 29 & 12 \\
Health and safety journals & 57 & 23 \\
Total & 150 & 62 \\
\hline
\end{tabular}

Table 4. Constraint to health and safety management.

\begin{tabular}{ccc}
\hline \multirow{2}{*}{ Constraint } & \multicolumn{2}{c}{ Frequency } \\
& $n$ & $\%$ \\
\hline Lack of adequate regulation & 85 & 32.4 \\
Lack of support & 71 & 27.1 \\
Lack of knowledge of details and implications & 37 & 14.1 \\
Lack of management commitment & 26 & 9.9 \\
None of these & 6 & 2.3 \\
\hline
\end{tabular}

perhaps through personal efforts, were aware of some safety regulations and their implications. A general lack of health and safety management systems and policies in organizations were identified. Furthermore, respondents noted that inadequate regulation and enforcement were huge barriers to better safety management in the sector.

It is suggested that in order to fully harness the potentials of the construction industry to the economic development of Nigeria, there is need, for a revision of the laws guiding health and safety management and regulation. Secondly, it is imperative that for this Act to be effective, a functional regulatory authority, perhaps modelled after the system in UK be established and empowered to carry out its regulatory and enforcement roles. The authors recognise that in view of the intricacies associated with health and safety management, the outcome of this paper may not be a perfect one. The result presented here is also an aggregated one; hence the issues raised may further be refined to guarantee better result. For instance, the questionnaire could be modified to incorporate questions on age, level of education, gender, among others. There may also be a need to carry out further studies in other sectors of the economy in order to have a balanced view of health and safety regulation in Nigeria. The final outcome would be an increase in productivity of the nation and a possible attainment of the vision 20:2020 of Federal Government. 


\section{REFERENCES}

[1] Health and Safety Commission, "Health and Safety Statistical Highlights,” Health and Safety Executive, Norwich, 2003.

[2] Eurostat, "European Social Statistics: Accidents at Work and Work Related Health Problems (Data 1994-2000)," European Communities, 2002.

[3] S. Pickvance, "Arguing the Business Case for Occupational Health,” Occupational Health Review, 2003.

[4] Institution of Occupational Safety and Health, "Professionals in Partnership,” Institution of Occupational Safety and Health, Leicester, 2001.

[5] I. Diugwu, "A Framework to Evaluate Critically the Health and Safety Strategies in Supply Chains in the UK,” Coventry University, Coventry, 2008.

[6] Health and Safety Executive, "A Guide to the Health and Safety etc. Act 1974: Guidance on the Act," HMSO, London, 1994.

[7] G. I. Idoro, "The Effect of Globalization on Safety in the Construction Industry in Nigeria,” Proceedings of International Symposium on Globalization and Construction, Thailand, November 2004, 10 p.

[8] G. I. Idoro, "Health and Safety Management Efforts as Correlates of Performance in the Nigerian Construction Industry,” Journal of Civil Engineering and Management, Vol. 14, No. 4, 2008, pp. 277-285. doi:10.3846/1392-3730.2008.14.27

[9] Federal Government of Nigeria, "The Factory Act of 1990,” Federal Government Press, Abuja, 1990.

[10] The Office for National Statistics, "Construction Statistics —No. 13, 2012 Edition,” 2012.

http://www.ons.gov.uk/ons/rel/construction/construction-stati stics/no--13--2012-edition/art-construction-statistics-annual-2012.html

[11] J. Dye and J. Sosimi, "United Kingdom National AccountsThe Blue Book,” Palgrave Macmillan, Basingstoke, 2010.

[12] O. A. Olatunji and N. Bashorun, "A System View of the Labour Profile Structure of the Construction Industry in the Developing Countries: Nigeria, A Case Study," International Conference in the Built Environment in the 21st Century (ICIBE), Kuala Lumpur, 13-15 June 2006, pp. 881-892.

[13] Health and Safety Executive, "Occupational Ill Health in the Construction Industry: Statistical Fact Sheet,” 2004. http://www.hse.gov.uk/statistics/industry/factcon.pdf

[14] Health and Safety Executive, "Health and Safety Offences and Penalties, 2003/2004,” 2005. http://www.hse.gov.uk/enforce/off03-04/off03-04.pdf

[15] A. Recio, R. de Alos-Moner and I. Olivares, "Construction in Spain: Towards a New Regulation?” Working Paper No. 13, Centre d'Estudis Sociològics sobre la Vida Quotidiana i el Treball (QUIT), Universitat Autònoma de Barcelona, 2006.

[16] International Labour Organization, "Safety and Health at Work,” International Labour Organization, 2010.

[17] Health and Safety Executive, "Construction Work Related Injuries and Ill Health,” 2012.
[18] M. G. Helander, "Safety Hazards and Motivation for Safe Work in the Construction Industry," International Journal of Industrial Ergonomics, Vol. 8, No. 3, 1991, pp. 205-223. doi:10.1016/0169-8141(91)90033-I

[19] Health and Safety Executive, "An Analysis of the Significant Causes of Fatal and Major Injuries in Construction in Scotland,” Research Paper 443, Health and Safety Executive, London, 2006.

[20] K. Dorji and B. H. W. Hadikusumo, "Safety Management Practices in the Bhutanese Construction Industry,” Journal of Construction in Developing Countries, Vol. 11, No. 2, 2006, pp. 53-75.

[21] M. J. Baker, “Sampling,” Marketing Review, Vol. 3, No. 1, 2002, pp. 103-120.

[22] E. Saenger, “An Investigation into a Future-Oriented Approach to Financial Reporting in South Africa," DCom Thesis, University of South Africa, 1991.

[23] W. D. Crano and M. B. Brewer, "Principles and Methods of Social Research,” 2nd Edition, Lawrence Erlbaum Associates, Mahwah, 2002.

[24] P. Levy and S. Lemeshow, "Sampling of Populations: Methods and Applications," Wiley, New York, 1991.

[25] W. G. Cochran, "Sampling Techniques," 3rd Edition, John Wiley \& Sons, New York, 1997.

[26] T. S. Yamane, “An Introductory Analysis,” 2nd Edition, Harper and Row, New York, 1967.

[27] G. D. Israel, “Sampling Issues: Nonresponse. Program Evaluation and Organizational Development,” IFAS, University of Florida, Gainesville, 1992.

[28] D. Holt and C. Kockelbergh, "Environmental Supply Chain Management in the UK-An Exploratory Analysis of Current Practices," Proceedings of the 12th Annual International Conference of the International Purchasing and Supply Education and Research Association (IPSERA), Budapest, 13-16 April 2003, pp. 678-689.

[29] L. Vassie, J. M. Tomas and A. Oliver, "Health and Safety Management in UK and Spanish SMEs: A Comparative Study," Journal of Safety Research, Vol. 31, No. 1, 2000, pp. 35-43. doi:10.1016/S0022-4375(99)00028-6

[30] S. Lammin, "Safety Management in Small Businesses," Ph.D. Thesis, Loughborough University, Loughborough, 2001.

[31] O. A. Adenuga, A. A. Soyingbe and O. M. Ajayi, “A Study of Selected Safety Measures on Construction Companies in Lagos, Nigeria," Proceedings of the Construction and Building Research Conference of the Royal Institution of Chartered Surveyors, Georgia Institute of Technology, Atlanta, 6-7 September 2007, pp. 678-689.

[32] I. Dalling, “The Future Is Unified: A Model for Integrated Management,” Quality World, Vol. 26, No. 4, 2000, pp. 34-39.

[33] J. Rimington, "Managing Risk-Adding Value: How Big Firms Manage Contractual Relations to Reduce Risk-A Study,” Health and Safety Executive, London, 1998.

[34] International Telecommunications Union (ITU), "ITU Digital Access Index: World'S First Global ICT Ranking,” 2003. http://www.itu.int/newsarchive/press_releases/2003/30.html 